\title{
Correlation between intake of omega-3 fatty acids and depressive and anxiety symptoms during pregnancy
}

\author{
Miriam Álvarez-Ramírez, ${ }^{1}$ Ma. Asunción Lara, ${ }^{2}$ José Miguel Cervantes-Alfaro, ${ }^{3}$ Virginia Angélica Robinson-Fuentes, \\ Jesús Alveano-Hernández ${ }^{4}$
}

División de Estudios de Posgrado, Laboratorio de Química Analítica, Facultad de Medicina Dr. Ignacio Chávez, Universidad Michoacana de San Nicolás de Hidalgo, Morelia, Michoacán, México.

2 Departamento de Modelos de Intervención, Instituto Nacional de Psiquiatría Ramón de la Fuente Muñiz, Ciudad de México, México.

3 División de Estudios de Posgrado, Laboratorio de Neurociencias y Neuroprotectores Endógenos, Facultad de Medicina Dr. Ignacio Chávez, Universidad Michoacana de San Nicolás de Hidalgo, Morelia, Michoacán, México.

${ }^{4}$ Escuela de Medicina, Universidad Vasco de Quiroga, Morelia, Michoacán, México.

\section{Correspondence:}

Miriam Álvarez Ramírez

División de Estudios de Posgrado, Laboratorio de Química Analítica, Facultad de Medicina Dr. Ignacio Chávez, Universidad Michoacana de San Nicolás de Hidalgo.

Astrónomos No. 28, Fracc Cosmos. C.P. 58050, Morelia, Michoacán, México.

Phone: (52) 443 155-8067

Email:malvarez.nutricion@gmail.com

Received: 14 March 2017

Accepted: 25 January 2018

\section{Citation:}

Álvarez-Ramírez, M., Lara, M. A., Cervantes-Alfaro, J. M., Robinson-Fuentes, V. A., Alveano-Hernández, J. Correlation between intake of omega-3 fatty acids and depressive and anxiety symptoms during pregnancy. Salud Mental, $41(1), 31-38$. doi: 10.17711/SM.0185-3325.2018.002

\begin{abstract}
Introduction. Anxiety and depression during pregnancy are disabling disorders associated to complications during the pregnancy, delivery, and postpartum period, with a significant prevalence, between 9 and $20 \%$, hence its importance. Nutritional factors, such as omega-3 fatty acids ( $\omega$-3FA) deficiency, have been related with both disorders during pregnancy, especially docosahexaenoic acid (DHA) and eicosapentaenoic acid (EPA). Objective. To evaluate the association between dietary intake of EPA and DHA, and anxiety symptoms (AS) and depressive symptoms (DS) in Mexican pregnant women. Method. The sample consisted of 151 women in the second trimester of pregnancy. Instruments included a Food Frequency Questionnaire, the Trait Anxiety Inventory, and the Edinburgh Postnatal Depression Scale. Results. A daily intake of DHA and EPA of $70 \mathrm{mg} / \mathrm{d}$ and $30 \mathrm{mg} / \mathrm{d}$, respectively, was found. The prevalence of AS was $44.4 \%$, and $17.9 \%$ for DS. We also found the correlation negatively moderate between dietary intake of DHA and EPA and AS $(p=.003, p=.017)$ and DS $(p=.001, p=.020)$ in the group of women who had a severely insufficient intake of $\omega-3 F A$. Discussion and conclusion. The statistical significance shows a negative correlation between variables and the dietary intake of $\omega$-3FA explains in a very small percentage the variability of AS and DS, according to their coefficient of determination. These results suggest the need for an investigation of this relationship through interventional studies.
\end{abstract}

Keywords: Fatty acids, omega-3, prenatal anxiety, prenatal depression.

\section{RESUMEN}

Introducción. La prevalencia de ansiedad y depresión en el embarazo oscilaentre 9 y $20 \%$. Poseen una gran importancia al ser trastornos incapacitantes asociados a complicaciones durante el embarazo, parto y postparto. Factores nutricionales, como la deficiencia de ácidos grasos omega-3 (AGw-3), se han relacionado con ambos trastornos durante el embarazo, especialmente el ácido docosahexaenoico (DHA) y el ácido eicosapentaenoico (EPA). Objetivo. Evaluar la asociación entre la ingesta dietética de EPA y DHA y los síntomas de ansiedad (SA) y depresión (DS) en mujeres embarazadas mexicanas. Método. Se entrevistó a 151 gestantes fueron entrevistadas en el segundo trimestre de embarazo. Los instrumentos de medición utilizados fueron: un Cuestionario de Frecuencia de Consumo de Alimentos, el Inventario de Ansiedad-Rasgo y la Escala de Depresión Postnatal de Edimburgo. Resultados. Se encontró una correlación negativa moderada entre la ingesta de DHA y EPA y los SA $(p=.003, p=.017)$ y SD $(p=.001, p=.020)$ en el grupo de mujeres con ingesta gravemente insuficiente. Se encontró una ingesta dietética diaria de DHA y EPA de $70 \mathrm{mg}$ y 30 mg, respectivamente. La prevalencia de SA fue $44.4 \%$ y de SD, $17.9 \%$. Discusión y conclusión. Aunque la significancia estadística mostró una correlación negativa entre variables, de acuerdo con el coeficiente de determinación, la ingesta dietética de AG $\omega$-3 explica en un escaso porcentaje la variabilidad de los SA y SD. Estos resultados sugieren la necesidad de investigar dicha relación por medio de estudios de intervención.

Palabras clave: Ácidos grasos, omega-3, ansiedad prenatal, depresión prenatal. 


\section{INTRODUCTION}

Pregnancy is a biopsychosocial condition that can increase the risk of mental disorders such as anxiety and depression in nearly $15.6 \%$ of pregnant women (Rahman et al., 2013). Anxiety symptoms (AS) during pregnancy have an international prevalence between $9.1 \%$ and $15.6 \%$ (Fadzil et al., 2013; Rubertsson et al., 2014) and a prevalence between $10 \%$ and $15 \%$ in Mexico (Ceballos-Martínez et al., 2010; Navarrete et al., 2012). Occasionally, AS during pregnancy are more frequent than depressive symptoms (DS) (Navarrete et al., 2012). A recent Mexican study shows a $16.6 \%$ prevalence of DS during pregnancy (Lara et al., 2015). AS and DS are not isolated disorders, they co-occur in $30 \%$ to $58 \%$ of patients with major depressive disorder (Field et al., 2010).

Both AS and DS have a negative impact in women's lives, their children, and their families. The World Health Organization recommends promoting low-cost interventions to improve maternal mental health (de Castro, Place, Villalobos, \& Allen-Leigh, 2015; Berenzon, Lara, Robles, \& Medina-Mora, 2013). However, these disorders do not represent a priority for the health care systems in Mexico, despite being associated to important effects on mother, fetus, neonate, and child (Ding et al., 2014; Hanley \& Oberlander, 2014). Depressed women have difficulties at work, higher prevalence of cardiovascular disease, stroke, and type 2 diabetes. Also, depressed and anxious mothers neglect their health and the health of their future child, leading to a deficient mother-baby bonding (de Castro et al., 2015). Furthermore, the fetuses of prenatally depressed women also show less total movement and an increased heart rate, have a delayed fetal growth, low fetal and birth weight, and low fetal length, with their subsequent risk of disease in adult life. Besides, newborns of depressed mothers are less responsive to stimulation in addition to other effects (Field, 2011).

There are many psychosocial risk factors which play an important role in the etiology of AS and DS. In Mexico, SD prevail in socioeconomic vulnerability and marginalization contexts (Lara, 2014; de Castro et al., 2015).

Recently, nutritional factors have been associated with AS and DS. The most studied nutritional risk factor is the intake of omega-3 polyunsaturated fatty acids ( $\omega-3 \mathrm{FA})$, especially their long-chain derivatives: docosahexaenoic acid

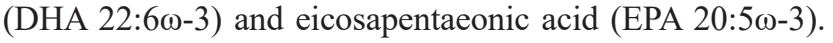
DHA and EPA are endogenously synthesized from $\alpha$-linolenic acid (ALA 18:3 $\omega-3$ ), but in a very limited amount, 9\% is converted to DHA and 21\% to EPA (Assies et al., 2010). Therefore, their intake should come from the diet, that is, from sources such as tuna, salmon, sardines, trout, school shark, and seafood. The current adequate intake, issued by the Institute of Medicine of the National Academies (IOM), for DHA, EPA, and ALA during pregnancy and lactation, are $300 \mathrm{mg} / \mathrm{d}, 220 \mathrm{mg} / \mathrm{d}$ and $1.4 \mathrm{~g} / \mathrm{d}$, respectively (Simopou- los, 2011). During the last trimester of pregnancy $67 \mathrm{mg} / \mathrm{d}$ of DHA are transferred to the fetus for the growth and development of its brain and retina. About $50 \%$ to $60 \%$ of the dry weight of an adult brain is composed of lipids, of which $20 \%$ corresponds to DHA (Liu, Green, Mann, Rapoport, \& Sublette, 2015). Thus, if the intake of $\omega$-3FA by the mother is insufficient, it is common that pregnancy depletes the mother's stock of cerebral and erythrocyte $\omega$-3FA (Morse, 2012). This deficiency, in the mother, is associated with a higher risk of mood disorders and preeclampsia, for example, whereas, in the newborn, it is associated with low neural development index, preterm birth, low height, and weight at birth (Van Eijsden, Hornstra, van der Wal, Vrijkotte, \& Bonsel, 2008).

An inverse association between a per capita intake of fish and an annual prevalence of depression was observed in the last 15 years (Grosso et al., 2014),which led to propose that dietary deficiency of $\omega$-3FA (measured as plasmatic, erythrocyte, and brain concentrations) is associated with higher depression, both in the perinatal period (Hibbeln, 2002; Markhus et al., 2013) and in other stages of life (Hoffmire, Block, Thevenet-Morrison, \& van Wijngaarden, 2012; Grosso et al., 2014; Su, Matsuoka, \& Pae, 2015).There is a relation between the intake of $\omega$-3FA and prenatal AS in animal and human models (Mizunoya et al., 2013; Vaz et al., 2013; Liu et al., 2015; Su et al., 2015).

The biological mechanisms proposed to explain this relation can be grouped according to the effect of $\omega-3 \mathrm{FA}$ in:

a) Functionality of the neuronal plasmatic membrane. DHA confers greater fluidity and permeability to plasma membrane, allowing an appropriate physical environment for the integral activity of different components present in neuronal membrane (Bazan, Musto, \& Knott, 2011).

b) Neuroendocrine and neuroinflammatory modulation. EPA and DHA are precursors of eicosanoids and docosanoids, biologically active lipid mediators, which have a wide variety of anti-inflammatory activities related to their antidepressant effect (Grosso et al., 2014).

c) Neurotransmission. DHA participates in serotoninergic, dopaminergic, and endocannabinoid neurotransmission systems. Its deficiency can affect the metabolism, release, recapture of neurotransmitter, and functionality of its receptors (Rizzo et al., 2012).

d) Synaptic plasticity. DHA participates in the synthesis of synaptic plasticity proteins in the hippocampus, like the brain-derived neurotrophic factor, which exerts antidepressant effects (Grosso et al., 2014).

Pregnancy is an adequate physiological condition to study the relation of $\omega-3 \mathrm{FA}$ and mental disorders for the ease with which maternal cerebral supplies of DHA are depleted (Markhus et al., 2013), and also because of the vulnerability of pregnant women to AS and/or DS (Wisner, Lara-Cinisomo, Pinheiro, \& Luther, 2014). The benefits of 
$\omega$-3FA consumption to prevent mental disorders in pregnant women have not been fully explored neither globally nor among Mexican population. Currently, the study of mental health during pregnancy has been oriented towards psychosocial factors associated to anxiety and depression (Navarrete et al., 2012; Lara et al., 2015), but little is known about the impact of nutrition on these disorders.

A deeper knowledge about the relation of $\omega$-3FA with AS and DS will allow the broadening the range of strategies for preventing and treating these perinatal mental disorders. Hence, the main objective of this study is to evaluate the association between dietary intake of EPA and DHA and anxiety and depressive symptoms in Mexican pregnant women. The study also aims to evaluate the dietary intake of $\omega$-3FA and the prevalence of AS and DS in Mexican pregnant women.

\section{METHOD}

\section{Study design and participants}

A cross-sectional and analytic study was performed. Between December, 2013 and July, 2014, 687 pregnant women receiving antenatal care were invited to participate. Only 151 of them met the inclusion criteria. The population sample was selected by convenience. Women were approached in the waiting rooms of an urban health center in the city of Morelia, Michoacan, Mexico. This is a community health center that provides prenatal care and other comprehensive medical care to low income women. Invitations to participate were extended to all pregnant women who met inclusion criteria: between 20 and 35 years, in their second trimester of pregnancy and who agreed to participate in the study. We excluded women with multiple pregnancies, acute chronic complications, diagnosed for major depressive disorder, or having consumed supplements with $\omega-3$ FA. Finally, women who did not complete the evaluation instruments were eliminated from the sample (Figure 1).

\section{Instruments}

The interview included four sections: 1. demographic data; 2 . AS; 3 . DS; and 4. dietary intake of $\omega$-3FA.A semi-structured interview type survey was performed by undergraduate students in nutrition, who applied all questionnaires; they were previously trained. The research team developed a manual which was given to each of the students to standardize the procedures of the interview.

\section{Demographic data}

Age, marital status, education level, occupation, and multiparity.

\section{Anxiety symptoms}

AS were assessed by the Trait-Anxiety scale of the Spanish version of the State-Trait Anxiety Inventory (STAI). The STAI consists of the state and trait subscales. We used the trait subscale that measures relatively stable individual propensity to respond with elevated anxiety, consisting of 20 statements in a Likert-type response scale ranging between one and four points. Its internal consistency varies between .85 and .87 (Spielberger \& Díaz-Guerrero, 1975). A cut-off $>40$ points on both state and trait scales yielded optimal sensitivity $(80.95 \%)$, specificity $(79.75 \%)$, positive predictive value (51.05\%), and negative predictive value (94\%) to determine cases of anxiety in pregnancy (Meades \& Ayers, 2011). We used a cut-off $>40$ points for determining women with AS, and a $>75$ percentile was scored as high AS.

\section{Depressive symptoms}

The Edinburgh Postnatal Depression Scale (EPDS), designed by Cox in 1987, was used to evaluate DS suffered during the seven previous days. It was validated in Mexican pregnant women by Alvarado-Esquivel, Sifuentes-Álvarez, Salas-Martínez, and Martínez-García (2006). The EPDS consists of 10 statements with four options about severity/intensity of symptoms rated in a zero to three score. A cut-off score of $\geq 12$ was used (Alvarado-Esquivel et al., 2006; Almanza-Muñoz, Salas-Cruz, \& Olivares-Morales, 2011). In Mexican women, the EPDS has shown a sensitivity of $75 \%$, a specificity of $93 \%$ (Alvarado-Esquivel et al., 2006), and a reliability of $\alpha=.87$ during pregnancy (Rosario-Juárez, Santos-García, Lara-Cantú, \& Almanza-Muñoz, 2009).

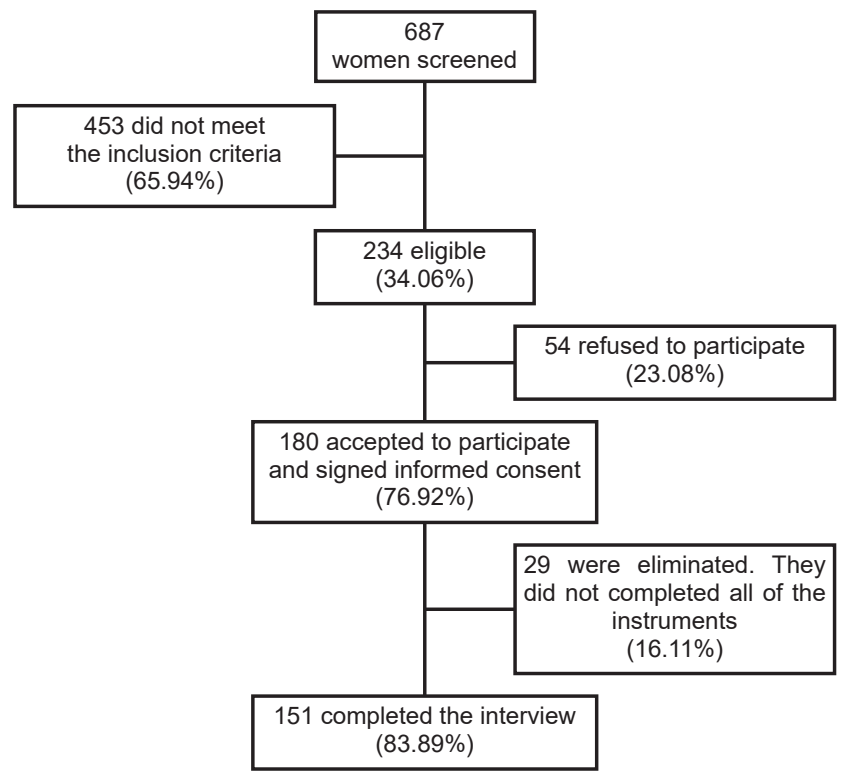

Figure 1. Participants flow from screening to assessment. 
Dietary intake of $\omega-3 F A$ and calculation of nutrient intakes

A semi-quantitative Food Frequency Questionnaire (FFQ) to obtain the average of $\omega$-3FA intake and the nutritional adequacy (NAI) was used. The FFQ was designed by the Instituto Nacional de Salud Pública (INSP) (Hernández-Ávila et al., 1998) and has already been validated in Mexican women residing in Mexico City (Parra et al., 2002). The questionnaire includes 104 items, divided in 10 food sections and an additional section inquiring about the dietary sources of $\omega$-3FA: fresh fish, sardines, tuna, and seafood, and a section of oils. We added extra food items as sources for $\omega-3 \mathrm{FA}$, such as cod, trout, salmon, and typical dry fish found in México, called charales. The questionnaire inquiries about the average frequency of consumption of each food item during the previous year. The frequency options of consumption are: never, less than once per month, 1-3 times per month, 1-2 per week, 3-4 per week, 5-6 per week, daily, 2-3 times per day, 4-5 per day, and 6 or more per day. The FFQ has proved to be useful in categorizing women by relative intakes, and can be used as a methodological tool in studies relating maternal diet during pregnancy (Parra et al., 2002). The average daily intake of DHA, EPA, and ALA was calculated using the software System of Evaluation of Nutritional Habits and Consumption of Nutriments (SNUT) v3.0, and developed at the INSP (Hernández-Ávila et al., 1998). SNUT uses the US Department of Agriculture food composition tables to obtain the nutrient content of $\omega$-3FA and its derivatives. Parra et al. (2002) evaluated the validity of this FFQ against a biochemical marker of fat intake, erythrocyte cell membrane phospholipid levels, during pregnancy. They concluded that this FFQ estimates the average long-term intakes of $\omega$-3FA and correlated well with their erythrocyte cell membrane phospholipid status.

Once the average intake of each $\omega$-3FA was calculated, we assessed NAI to observe the degree of dietary insufficiency, comparing the estimated average daily consumption with the adequate intake of each $\omega$-3FA, established by the IOM (Simopoulos, 1999). NAI between $90 \%$ and $110 \%$ indicates dietary sufficiency, a value between $75 \%$ and $89 \%$ indicates mild insufficiency, between $74 \%$ and $50 \%$ indicates moderate insufficiency, and less than $50 \%$ stands for severe insufficiency (Córdoba-Caro, Luego, \& García, 2012).

\section{Statistical analysis}

Using a Kolmogorov-Smirnov test, a non-normal distribution was determined for the daily intake of $\omega-3 \mathrm{FA}$, and for the anxiety and depression test rates; therefore, non-parametric tests were deemed appropriate. In the descriptive analysis we used frequencies and percentage to determine demographic and psychological characteristics of pregnant women. Categorical variables for establishing insufficient intake of DHA, EPA, and ALA $(<50 \%$ of daily recom- mended intake) were generated. Median, minimum, and maximum values to determine dietary intake and NAI of $\omega-3 F A$ were used. Spearman rank correlation test and simple linear regression models were generated to evaluate the association between the psychological scales (STAI-T and EPDS) and the dietary intake of DHA and EPA. As a measure of goodness of fit, the coefficient of determination was used. The sample size was calculated with statistic data published (Almanza-Muñoz et al., 2011). A type 1 error of .05 was established, with a confidence interval of $95 \%$ ( $z=$ 1.96). Statistical analysis was conducted in SPSS 20.0.

\section{Ethical considerations}

The methodology adhered to the Ethical Principles for Medical Research Involving Human Subjects of the Declaration of Helsinki (World Medical Association, 2013). Informed consent was obtained from each participant. The protocol was evaluated and approved by the Bioethics Committee of the Hospital de la Mujer in Morelia.

\section{RESULTS}

Demographic and psychological characteristics are presented in Table 1. The average age of the sample was 25.66

Table 1

Demographic and psychological characteristics of pregnant women $(N=151)$

\begin{tabular}{lrl}
\hline & \multicolumn{2}{l}{$f(\%)$} \\
\hline Marital status & & \\
Cohabitating & 67 & $(44.4 \%)$ \\
Married & 54 & $(35.8 \%)$ \\
Single & 29 & $(19.2 \%)$ \\
Divorced & 1 & $(.7 \%)$ \\
Education level & & \\
Elementary school & 26 & $(17.22 \%)$ \\
Middle school & 54 & $(35.8 \%)$ \\
High school/equivalent & 46 & $(30.5 \%)$ \\
Bachelor degree/equivalent & 25 & $(16.6 \%)$ \\
Occupation & & \\
Home & 93 & $(61.6 \%)$ \\
Employee & 32 & $(21.2 \%)$ \\
Student & 19 & $(12.6 \%)$ \\
Own business & 7 & $(4.6 \%)$ \\
Multiparity & & \\
Primiparous & 52 & $(34.4 \%)$ \\
Multiparous & 99 & $(65.6 \%)$ \\
Anxiety symptoms (STAI-T) $\geq 40$ & 67 & $(44.4 \%)$ \\
High anxiety symptoms & & \\
(STAI-T) > 75th percentile & $21 \quad(13.9 \%)$ \\
Depressive symptoms (EPDS) $\geq 12$ & 27 & $(17.9 \%)$ \\
\hline
\end{tabular}

Note: STAI-T = State-Trait Anxiety Inventory; EPDS = Edinburgh Postnatal Depression Scale. 
Table 2

Dietary intake and nutritional adequacy index of omega-3 fatty acid obtained through the Mexican FFQ. $(N=151)$

\begin{tabular}{lcc}
\hline & $\begin{array}{c}\text { Dietary intake } \\
\text { Median (Min-Max) }\end{array}$ & $\begin{array}{c}\text { Nutritional adequacy index } \\
\text { Median (Min-Max) }\end{array}$ \\
\hline $22: 6 \omega-3$ & $70 \mathrm{mg} / \mathrm{d}(0-720)$ & $23.30 \%(0-240)$ \\
$20: 5 \omega-3$ & $30 \mathrm{mg} / \mathrm{d}(0-280)$ & $13.64 \%(0-127.27)$ \\
$18: 3 \omega-3$ & $980 \mathrm{mg} / \mathrm{d}(0-5220)$ & $70.00 \%(0-372.86)$
\end{tabular}

Number and percentage of women with a dietary intake $<50 \%$ of daily recommended intake

\begin{tabular}{lr}
$22: 6 \omega-3^{a}$ & $122(80.8 \%)$ \\
$20: 5 \omega-3^{b}$ & $138(91.4 \%)$ \\
$18: 3 \omega-3^{c}$ & $40(26.5 \%)$ \\
\hline
\end{tabular}

Note: FFQ: Food Frequency Questionnaire; aDaily recommended intake of DHA: $300 \mathrm{mg} / \mathrm{d}$; baily recommended intake of EPA: $220 \mathrm{mg} / \mathrm{d}$; ' Daily recommended intake of ALA: $1400 \mathrm{mg} / \mathrm{d}$.

$(S D=4.50)$ years. AS were more frequent than DS $(44.4 \%$ vs. $17.9 \%$, respectively), and $13.9 \%$ of the women had high AS (STAI-T $>75^{\text {th }}$ percentile).

Table 2 shows dietary intake and NAI of $\omega-3 F A$. Daily intakes of DHA, EPA, and ALA were $70 \mathrm{mg} / \mathrm{d}, 30 \mathrm{mg} / \mathrm{d}$, and $980 \mathrm{mg} / \mathrm{d}$, respectively; NAI was low for all of the assessed fatty acids. The most insufficient $\omega$-3FA was EPA and its NAI was $13.64 \%$; this indicates that the sample is consuming only $13.64 \%$ of daily recommendation of EPA, followed by DHA (23.30\%). Likewise, $91.4 \%$ and $80.8 \%$ of the pregnant women had a severe insufficiency $(\leq 50 \%$ of NAI) of EPA and DHA, respectively.

Table 3 shows the Spearman's correlations between DHA and EPA, and scores from STAI-T and EPDS questionnaires. These variables were analyzed for the entire population Spearman's correlations were then performed only for pregnant women who had a severely insufficient intake of DHA and EPA ( $n=122$ and $n=138$, respective-

Table 3

Correlation between dietary intake of DHA and EPA and STAI-T and EPDS scores

\begin{tabular}{lcc}
\hline & Spearman's Rho & $P$ value \\
\hline 22:6 $\omega-3^{\mathrm{a}}(N=151)$ & & \\
STAI-T scores & -.146 & .073 \\
EPDS scores & -.134 & .101 \\
20:5 $\omega-3^{\mathrm{a}}(N=151)$ & & \\
STAI-T scores & -.175 & $.032^{*}$ \\
EPDS scores & -.142 & .082 \\
22:6 $\omega-3^{\mathrm{b}}(N=122)$ & & \\
STAI-T scores & -.266 & $.003^{*}$ \\
EPDS scores & -.291 & $.001^{* *}$ \\
20:5 $\omega-3$ b $(N=138)$ & & \\
STAI-T scores & -.203 & $.017^{*}$ \\
EPDS scores & -.198 & $.020^{*}$ \\
\hline
\end{tabular}

Note: a Correlation in the entire sample; ${ }^{\mathrm{b} C}$ Correlation in the group of women who had an insufficient dietary intake $(\leq 150 \mathrm{mg} \mathrm{DHA} / \mathrm{d}, \leq 110 \mathrm{mg} \mathrm{EPA} / \mathrm{d})$; ${ }^{*} p<.05 ;{ }^{* *} p<.001$ ly). In the analysis with the entire sample, a significant negative correlation was found only between intakes of EPA and STAI-T scores (Rho $=-.175 ; p=.032$ ). For the group of women with severe insufficiency, there was a significant negative correlation between DHA and STAI-T $(p=.003)$ and EPDS $(p=.001)$ scores. A significant negative correlation with EPA in both mental health scales was also found ( $p=.017$ and $p=.020$, respectively).

Figure 2 shows the dispersion models, for these group of women only. To assess the proportion of total variability of the dependent variables (AS and DS), we obtained the coefficient of determination $\left(\mathrm{R}^{2}\right)$. In all the dispersion models, $\mathrm{R}^{2}$ showed a low predictive capacity to the variable, one value on $\mathrm{x}$-axis corresponding to several values in y-axis. The $8.5 \%$ and $8.9 \%$ of the variability of AS and DS, respectively, can be attributed to a relationship with an intake of DHA; and $2.7 \%$ and $1.5 \%$, can be attributed to a relationship with an intake of EPA.

\section{DISCUSSION AND CONCLUSION}

In this study, a moderate weak negative correlation between $\omega-3 \mathrm{FA}$ and AS and DS in pregnant women was found, which was significant only when we analyzed women who had an insufficient dietary intake of DHA and EPA. We decided to exclude from correlation's analyses those women who covered or exceeded adequate intake to avoid any bias and reach sound results when analyzing a sample similar to the pregnant Mexican women population. Some cross-sectional studies indicate that people consuming fish and seafood less than once a week have higher risk of developing depressive disorders (Hibbeln, 2002; Markhus et al., 2013; Grosso et al., 2014). However, these results are inconclusive given that it is unknown if one event precedes the other, that is, if eating fish precedes depressive disorders, or if such disorders lead to consuming less fish. In that same context, in cohort studies it has been found that a higher intake of fish together with a higher intake of EPA and DHA were associated with lower rates of DS (Li, Dai, Ekperi, Dehal, \& Zhang, 2011; Grosso et al., 2014; Su et al., 2015). Murine models have shown that intake of DHA causes a reduction in the development of behaviors similar to depression (Mizunoya et al., 2013; Su et al., 2015). In humans, Vaz et al. (2013) recorded that a lower intake of $\omega-3 F A$ and a lower frequency of fish and seafood consumption were associated with higher incidence of AS in pregnant women.

This moderate correlation in our study may imply that, as the insufficiency dietary intake of DHA and EPA in pregnant women becomes more severe, the scores of STAI-T and EPDS increase slightly. It must be stated that in order to observe such a tendency, the intake of EPA and DHA must be severely insufficient ( $\leq 50 \%$ of the daily recommendation), which seems very likely in Mexico, given that 

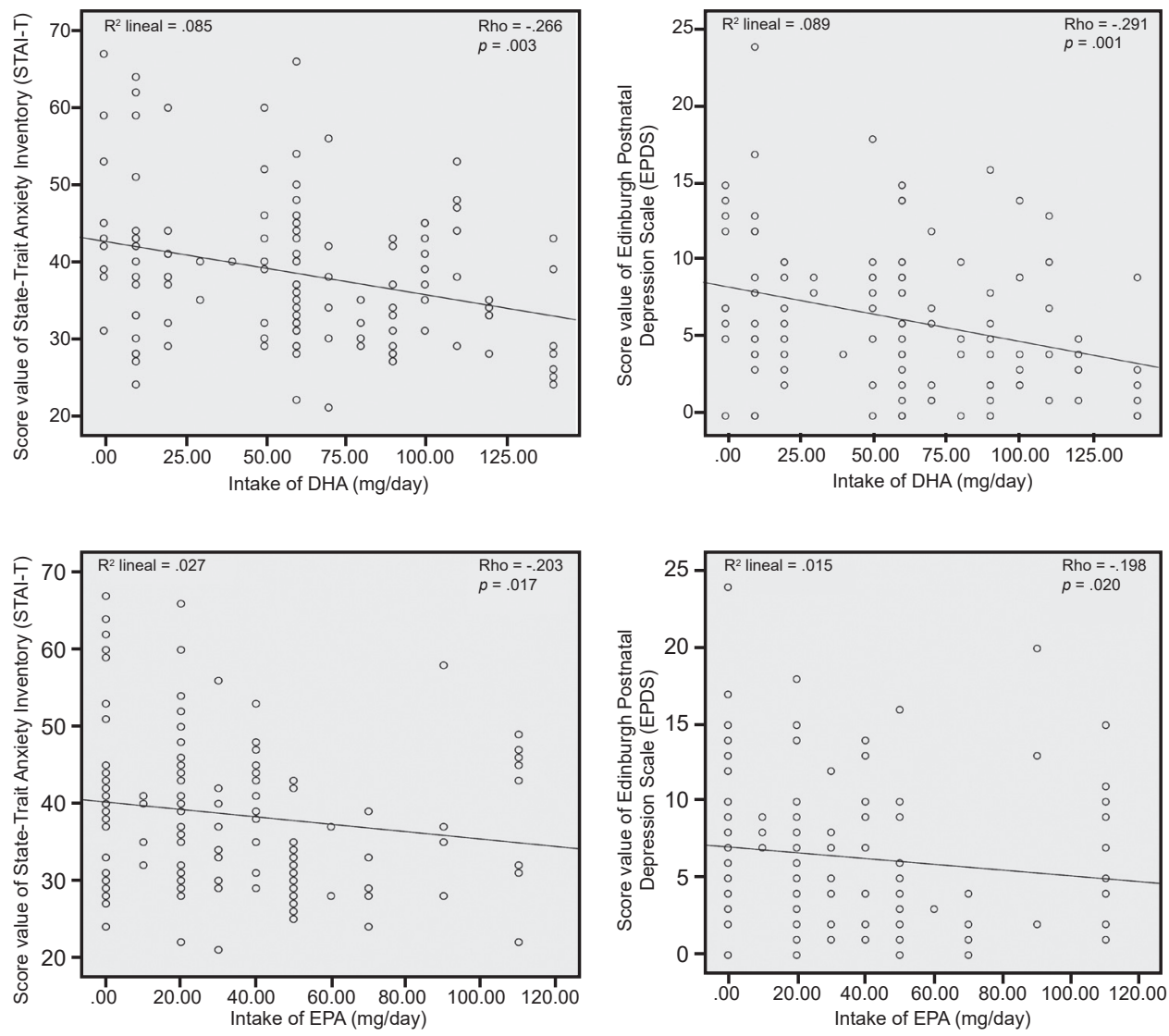

Figure 2. Correlation between intake of $\omega-3 F A$ (DHA and EPA), and score values of applied scales assessed (STAI-T and EPDS) during the second half of pregnancy in a group of women with insufficient intake.

Mexicans consume fish and seafood approximately once a month (Parra et al., 2002). Nevertheless, considering that the present study is a cross-sectional type, a cause-effect relationship cannot be established. It is suggested to conduct intervention studies in order to assess the efficacy and role played by $\omega-3 \mathrm{FA}$ in AS and DS.

In terms of the studied nutritional variables, it is worrisome that $80.8 \%$ and $91.4 \%$ of pregnant women had a dietary intake lower than the $50 \%$ of the daily recommendation of DHA and EPA, respectively. Such findings coincide with a study from the ENSANUT 2006 that found that the Mexican adult population has an average intake of 300 $\mathrm{mg} / \mathrm{d}$ of $\omega-3 \mathrm{FA}$, of which $270 \mathrm{mg}$ correspond to ALA and less than $30 \mathrm{mg}$ correspond to DHA (Ramírez-Silva, Villalpando, Moreno-Saracho, \& Bernal-Medina, 2011); in this study, we found intake levels even lower than those. Today, western societies are characterized by a decrease in $\omega-3 \mathrm{FA}$ intake, mainly because EPA and DHA can only be found in fish and seafood products, which are much more expensive than food with other FA, like omega-6 fatty acids. It is worth mentioning that as Morelia is not a coastal city, it would be interesting to compare the dietary intake of $\omega-3 \mathrm{FA}$, and AS and DS between non-coastal and coastal regions of Mexico, where people are more likely to consume higher amounts of fish and sea food.

Prevalences of $44.4 \%$ and $17.9 \%$ in AS and DS, respectively, were found. The $44.4 \%$ of women with AS is similar to the prevalence reported in the UK $(36 \%-56 \%)$ and Uzbekistan (38\% - 42\%) (Meades \& Ayers, 2011). However, our results in the prevalence of AS differ considerably from other previous Mexican perinatal studies, which range from $8.1 \%$ to $16 \%$, based on self-report questionnaires (Ceballos-Martínez et al., 2010; Navarrete et al., 2012). This figure is in agreement with our results obtained at the cut-off point above the $75^{\text {th }}$ percentile (13.9\%). Despite these figures, AS during pregnancy has received little attention (Navarrete et al., 2012). On the other hand, our prevalence of DS was similar to the international report of $18.4 \%$ (Gavin et al., 2005), and to the $16.6 \%$ prevalence in Mexican pregnant population (Lara et al., 2015). However, our percentage of prevalence is higher than the $12.8 \%$ reported by Bennett, Einarson, Taddio, Koren, and Einarson (2004) for the second trimester of pregnancy. These comparisons show that AS and DS are common in the studied population. 
There are two limitations in this cross-sectional study. First, we decided to use a convenient non-probabilistic sampling procedure; pregnant women who had enough time and willingness to answer all interview were intentionally selected. Non-randomized sampling limits the scope of generalization to the population as a whole, since some of its characteristics may not be well represented in the sample. The second limitation of the study refers to the waiting rooms, where interviews were conducted, since there was not enough privacy to apply the scales of mood disorders. This situation could lead the participants to responding with a high social desirability for fear of being heard by other people.

These results are promising because they imply that dietary insufficiency of EPA and DHA may be related to the presence of AS and DS. In addition, they reveal that a low intake of DHA and EPA is a predisposing but not triggering factor of AS and DS in pregnant women, suggesting that dietary interventions can be used in order to prevent or reduce the prevalence of AS and DS in pregnant women. It is worth mentioning that women are reluctant to take medication during pregnancy (Lara, 2014), and supplementation with $\omega$-3FA may be a more accepted intervention for AS and DS. Perinatal mental health has been given little attention in Mexico, so these data aim to contribute to increasing evidence on its importance and possible interventions in order to reduce the potential negative effects on women's and infant's physical and mental health. The significant percentage of pregnant women with AS and DS must get the attention of health institutions in order to adopt reliable tools to identify women at risk. This study is the first one in Mexico that evaluates the relationship between mental disorders and nutritional factors such as $\omega$-3FA.

\section{Funding}

This study was supported by the Consejo Nacional de Ciencia y Tecnología de México (CONACYT) grant 286473.

\section{Conflict of interests}

All authors declare that they have no conflict of interest.

\section{Acknowledgements}

The authors wish to thank the undergraduate female students of the Nutrition degree of the UMSNH and UNLA for their technical support during interviews and application of questionnaires to patients.

\section{REFERENCES}

Almanza-Muñoz, J., Salas-Cruz, C., \& Olivares-Morales, A. (2011). Prevalencia de depresión postparto y factores asociados en pacientes puérperas de la Clínica de especialidades de la Mujer. Revista de Sanidad Militar, 65(3), 78-86.

Alvarado-Esquivel, C., Sifuentes-Álvarez, A., Salas-Martínez, C., \& MartínezGarcía, S. (2006). Validation of the Edinburgh Postpartum Depression Scale in a population of puerperal women in Mexico. Clinical Practice and Epidemiology in Mental Health, 2(33), 1-5, doi: 10.1186/1745-0179-2-33.
Assies, J., Pouwer, F., Lok, A., Mocking, R., Bockting, C., Visser, I., ...Schene, A. (2010) Plasma and Erythrocyte Fatty Acids Patterns in Patients with Recurrent Depression: A Matched Case-Control Study. PLOS ONE, 5(5), 1-9.

Bazan, N., Musto, A., \& Knott, E. (2011). Endogenous signaling by omega-3 DHA derived mediators sustains homeostatic synaptic and circuitry integrity. Molecular Neurobiology. 44, 216-222.

Bennett, H., Einarson, A., Taddio, A., Koren, G., \& Einarson, T. (2004). Depression during pregnancy. Overview of Clinical Factors. Clinical Drug Investigation, 24(3), 157-179.

Berenzon, S., Lara, M. A., Robles, R., \& Medina-Mora, M. E. (2013). Depresión: estado del conocimiento y la necesidad de políticas públicas y planes de acción en México. Salud Pública de México, 55(1), 74-80.

Ceballos-Martínez, I., Sandoval-Jurado, L., Jaimes-Mundo, E., Medina-Peralta, G., Madera-Gamboa, J., \& Fernández-Arias, Y. F. (2010). Depresión durante el embarazo Epidemiología en mujeres mexicanas. Rev Med Inst Mex Seguro Soc, 48(1), 71-74.

Córdoba-Caro, L. G., Luego, L. M., \& García, V. (2012) Adecuación nutricional de la ingesta de los estudiantes de secundaria de Badajoz. Nutrición Hospitalaria, 27(4), 1065-1071.

De Castro, F., Place, J. M., Villalobos, A., \& Allen-Leigh, B. (2015) Sintomatología depresiva materna en México: prevalencia nacional, atención y perfiles poblacionales de riesgo. Salud Pública de México, 57, 144-154.

Ding, Z., Wu, Y., Xu, S., Zhu, R., Jia, X., Zhan, S., ... Tao, F. (2014). Maternal anxiety during pregnancy and adverse birth outcomes: A systematic review and meta-analysis of prospective cohort studies. Journal of Affective Disorders, 159, 103-110. doi: 10.1016/j.jad.2014.02.027

Fadzil, A., Balakrishnan, K., Razali, R., Sidi, H., Malapan, T., Japaraj, R. P., ... Manaf, M. R (2013). Risk factors for depression and anxiety among pregnant women in Hospital Tuanku Bainum, Ipoh, Malaysia. Asia-Pacific Psychiatry, 5(1), 7-13. doi: 10.1111/appy.12036.

Field, T., Diego, M., Hernández-Reif, M., Figueiredo, B., Deeds, O., Ascencio, A., ... Kuhn, C. (2010) Comorbid depression and anxiety effects on pregnancy and neonatal outcome. Infant Behavior \& Development, 33(1), 23-29.

Field, T. (2011) Prenatal depression effects on early development: A review. Infant Behavior and Development. 34(1), 1-14. doi: 10.1016/j.infbeh.2010.09.008

Gavin, N. I., Gaynese, B. N., Lohr, K. N., Meltzer-Brody, S., Gartlehner, G., \& Swinson, T. (2005) Perinatal depression: a systematic review of prevalence and incidence. Obstetrics \& Gynecology, 106(5), 1071-1083.

Grosso, G., Galvano, F., Marventano, S., Malaguarnera, M., Bucolo, C., Drago, F., \& Caraci, F. (2014). Omega-3 fatty acids and depression: Scientific Evidence and Biological Mechanisms. Hindawi Publishing Corporation. Oxidative Medicine and Cellular Longevity, 313570, 1-16. doi: 10.1155/2014/313570

Hanley, G., \& Oberlander, T. (2014). The effect of perinatal exposures on the infant: antidepressants and depression. Best Practice \& Research Clinical Obstetrics \& Gynaecology, 28(1), 37-48. doi: 10.1016/j.bpobgyn.2013.09.001

Hernández-Ávila, M., Romieu, I., Parra, S., Hernández-Ávila, J. E., Madrigal, H., $\&$ Willett,W. (1998). Validity and reproducibility a food frequency questionnaire to assess dietary intake of women living in Mexico City. Salud Publica de México, 40(2), 133-140.

Hibbeln, J. R. (2002). Seafood consumption, the DHA content of mother's milk and prevalence rates of postpartum depression: a cross-national, ecological analysis. Journal of Affective Disorders, 69(1-3), 15-29.

Hoffmire, C., Block, R., Thevenet-Morrison, K., \& van Wijngaarden, E. (2012). Associations between omega-3 poly-unsaturated fatty acids from fish consumption and severity of depressive symptoms. An analysis of the 20052008 National Health and Nutrition Examination Survey. Prostaglandins, Leukotrienes and Essential Fatty Acids, 86(4-5), 155-160. doi: 10.1016/j. plefa.2012.03.003

Lara, M. A. (2014). Perinatal Depression in Mexican Women: Prevalence, Risk Factors, and Prevention of Postpartum Depression. In: K. Wisner, S. Lara-Cinisomo, (Eds.), Perinatal Depression Among Spanish-Speaking and Latin American Women. A Global Perspective on Detection and Treatment (pp. 1-13). New York: Springer. doi: 10.1007/978-1-4614-8045-7

Lara M. A., Navarrete, L., Nieto, L., Barba, J. P., Navarro, J. L., \& Lara-Tapia, H. (2015). Prevalence and incidence of perinatal depression and depressive symp- 
toms among Mexican women. Journal of Affective Disorders, 175, 18-24. doi: 10.1016/j.jad.2014.12.035

Li, Y., Dai, Q., Ekperi, L. I., Dehal, A., \& Zhang, J. (2011). Fish consumption and severely depressed mood, findings from the first national nutrition follow-up study. Psychiatry Research, 190(1), 103-109. doi: 10.1016/j.psychres.2011.05.012

Liu, J., Green, P., Mann, J., Rapoport. S., \& Sublette, E. (2015). Pathways of polyunsaturated fatty acid utilization: Implications for brain function in neuropsychiatric health and disease. Brain Research, 1597, 220-246. doi: 10.1016/j. brainres.2014.11.059

Markhus, M. W., Skotheim, S., Graff, I. E., Frøyland, L., Braarud H. C., Stormark, J. M., \& Malde, M. K. (2013). Low Omega-3 Index in Pregnancy Is a Possible Biological Risk Factor for Postpartum Depression. PLOS ONE, 8(7), 1-12. doi: 10.1371/journal.pone.0067617

Meades, R., \& Ayers, S. (2011). Anxiety measures validated in perinatal populations: A systematic review. Journal of Affective Disorders, 133(1-2), 1-15, doi: 10.1016/j.jad.2010.10.009

Mizunoya, W., Ohnuki, K., Baba, K., Miyahara, H., Shimizu, N., Tabata, K., ... Ikeuchi, Y. (2013). Effect of dietary fat type on anxiety-like and depression-like behavior in mice. Springer Plus, 2(165), 1-9. doi: 10.1186/2193-1801-2-165

Morse, N. (2012). Benefits of Docosahexaenoic Acid, Folic Acid, Vitamin D and Iodine on Foetal and Infant Brain Development and Function Following Maternal Supplementation during Pregnancy and Lactation. Nutrients, 4(7), 799-840. doi: $10.3390 /$ nu 4070799

Navarrete, L. E., Lara, M. A., Navarro, C., Gómez, M. E., \& Morales, F. (2012). Factores psicosociales que predicen síntomas de ansiedad postnatal y su relación con los síntomas depresivos en el postparto. Revista de Investigación Clínica, 64(6), 625-633.

Parra, M. S., Schnaas, L., Meydan, M., Perroni, E., Martínez, S., \& Romieu, I. (2002). Erythrocyte cell membrane phospholipids levels compared against reported dietary intakes of polyunsaturated FA in pregnant Mexican women. Public Health Nutrition, 5(6a), 931-937. doi:10.1079/PHN2002381

Rahman, A., Fisher, J., Bower, P., Luchters, S., Tran, T., Yasamy, M. T., ... Waheed, W. (2013). Interventions for common perinatal mental disorders in women in lowand middle- income countries: a systematic review and meta-analysis. Bulletin of the World Health Organization, 91, 593-601. doi: 10.2471/BLT.12.109819

Ramírez-Silva, I., Villalpando, S., Moreno-Saracho, J., \& Bernal-Medina, D. (2011). Fatty acids intake in the Mexican population. Results of the National Nutrition Survey 2006. Nutrition \& Metabolism, 8(33), 1-10, doi: 10.1186/1743-70758-33

Rizzo, A. M., Corsetto, P. A., Montorfano, G., Opizzi, A., Faliva, M., Giacosa, A., .. Rondanelli, M. (2012). Comparison between the AA/EPa ratio in depressed and non-depressed elderly females: Omega- 3 fatty acids supplementation correlates with improved symptoms but does not change immunological parameters. $\mathrm{Nu}$ trition Journal, 11(82), 1-11.

Rosario-Juárez, I., Santos-García, R., Lara-Cantú, M. A., \& Almanza-Muñoz, J. J. (2009). Consistencia interna y análisis factorial de la Escala de Depresión Postparto de Edimburgo en mujeres mexicanas embarazadas y puérperas. Reporte preliminar. Revista Neurología, Neurocirugía y Psiquiatría, 42(1-4), 1-6.

Rubertsson, C., Hellström, J., Cross, M., \& Sydsjö, G. (2014). Anxiety in early pregnancy: prevalence and contributing factors. Archives of Women's Mental Health, 17(3), 221-228. doi: 10.1007/s00737-013-0409-0

Simopoulos, A. P. (1999). Essential fatty acids in health and chronic disease. The American Journal of Medical Nutrition, 70(3), 560s-569s. doi: 10.1093/ ajcn/70.3.560s

Simopoulos, A. P. (2011). Evolutionary Aspects of Diet: The Omega-6/Omega-3 Ratio and the Brain. Molecular Neurobiology, 44(2), 203-215. doi: 10.1007/ s12035-010-8162-0

Spielberger, C., \& Díaz-Guerrero, R. (1975). IDARE Inventario de Ansiedad: Rasgo-Estado. Manual e Instructivo. México: El Manual Moderno, 1-28.

Su, K. P., Matsuoka, Y., \& Pae, C.U. (2015). Omega-3 Polyunsaturated Fatty Acids in Prevention of Mood and Anxiety Disorders. Clinical Psychopharmacology, 13(2), 129-137. doi: 10.9758/cpn.2015.13.2.129

Van Eijsden, M., Hornstra, G., van der Wal, M., Vrijkotte, T., \& Bonsel, G. (2008). Maternal $\omega-3, n-6$, and trans fatty acid profile early in pregnancy and term birth weight: a prospective cohort study. The American Journal of Clinical Nutrition, 87(4), 887-95.

Vaz, J., Kac, G., Emmett, P., Davis, J. M., Golding, J., \& Hibbeln, J. (2013). Dietary Patterns, $\omega-3 F A$ tty Acids Intake from Seafood and High Levels of Anxiety Symptoms during Pregnancy Findings from the Avon Longitudinal Study of Parents and Children. PLOS ONE, 8(7), 1-9, doi: 10.1371/journal.pone.0067671

Wisner, K. L., Lara-Cinisomo, S., Pinheiro, E., \& Luther, J. (2014). Characteristics of Hispanic Women Screened for Postpartum Depression. In: K. Wisner, S. Lara-Cinisomo (Eds.) Perinatal Depression Among Spanish-Speaking and Latin American Women. A Global Perspective on Detection and Treatment (pp. 1-13), New York: Springer. doi: 10.1007/978-1-4614-8045-7_1

World Medical Association. (2013). Declaración de Helsinki. Principios éticos para las investigaciones con seres humanos. $64^{\mathrm{a}}$ Asamblea General, Fortaleza, Brasil, octubre de 2013. Retrieved from: https://www.wma.net/es/policies-post/ declaracion-de-helsinki-de-la-amm-principios-eticos-para-las-investigaciones-medicas-en-seres-humanos/ 